\title{
Antidepressant-Like Effects of Selected Crude Extracts of Pilea microphylla in Mice Model of Depression
}

\author{
${ }^{1}$ Amir Modaressi Chahardehi, ${ }^{1}$ Darah Ibrahim, \\ ${ }^{2}$ Fabrid Aboulhasani and ${ }^{3}$ Shaida Fariza Sulaiman \\ ${ }^{1}$ Industrial Biotechnology Research Laboratory, \\ School of Biological Sciences, Universiti Sains Malaysia, 11800 Minden, Penang, Malaysia \\ ${ }^{2}$ Department of Anatomy, Medical School, Tehran University of Medical Sciences, Iran \\ ${ }^{3}$ Phytochemistry Laboratory, School of Biological Sciences, \\ Universiti Sains Malaysia, 11800 Minden, Penang, Malaysia
}

Received 2012-03-19, Revised 2013-02-24; Accepted 2013-03-19

\begin{abstract}
The present study was undertaken to investigate the effect of selected crude extracts namely, Methanol (ME I), Chloroform Extract (CE II) and Ethyl Acetate (EAE II) extracts of Pilea microphylla on depression in mice. In the present study, the antidepressant effect of $P$. microphylla was examined due to its rich flavonoid contents in the Urticaceae family using two behavioral models, the Forced Swimming Test (FST) and Tail Suspension Test (TST) in mice. Selected crude extracts from Pilea microphylla produced an antidepressant-like effect, since the acute treatment of mice with extracts by intraperitoneal (i.p.) route significantly reduced the immobility time in the FST (50 and $100 \mathrm{mg} \mathrm{kg}^{-1}$ ) and TST (50 and $100 \mathrm{mg} \mathrm{kg}^{-1}$ ), as compared to positive controls (haloperidol and fluoxetine) at 1 and $10 \mathrm{mg} \mathrm{kg}^{-1}$, respectively. The results showed that ME I, CE II and EAE II at dose of $100 \mathrm{mg} \mathrm{kg}^{-1}$ of body weight decreased immobility time with the increase swimming time with respect to the first day $(\mathrm{p}<0.05)$. Among all the three selected extracts with two doses administered there were differences compared to the control group, EAE II led to reduction of immobility time, in the FST method by $38.50 \%$ for $50 \mathrm{mg} \mathrm{kg}^{-1}$ to as much as $75.97 \%$ for $100 \mathrm{mg} \mathrm{kg}^{-1}$. Similar results of increased antidepressant effect, that was, of immobility time depending on the concentration administered, were obtained with the TST method. However, EAE II and CE II extract at dose of $100 \mathrm{mg}$ $\mathrm{kg}^{-1}$ were obtained as best to choose an antideprssant activity. However, amounts of phenolic and flavonoid groups were found in CE II extract. As a conclusion treatment using selected crude extracts of $P$. microphylla had an antidepressant-like effect across models. Reduced immobility and decreasing freezing were observed in FST and TST tests. Therefore, P. microphylla may be served as a potential resource for natural psychotherapeutic agent against depression. The present study clearly demonstrated that Pilea microphylla exerts an antidepressant effect in these two behavioural models. It may be due to present of flavonoids. This is consistent with the hypothesis that enhanced uptake of flavonoids groups might have antidepressant-like effects. However, further studies are still required.
\end{abstract}

Keywords: Pilea Microphylla, Antidepressant Activity, Forced Swimming Test (FST), Tail Suspension Test (TST), Differences Compared, Similar Results, Increased Antidepressant

\section{INTRODUCTION}

Depression is a chronic, recurring and potentially lifethreatening illness that affect up to $20 \%$ of the population across the globe. This disease is one of the top ten causes of morbidity and mortality worldwide and represents a high cost to countries economy. The main symptom of depression is characterized by a pervasive low mood, feeling of helplessness, loss of interest and loss of pleasure in most of the usual activities (Posser et al.,

Corresponding Author: Amir Modaressi Chahardehi, Industrial Biotechnology Research Laboratory, School of Biological Sciences, Universiti Sains Malaysia, 11800 Minden, Penang, Malaysia 
2009). Antidepressant medications represent the best established treatment for major depressive disorder, they have adverse effects that can compromise the therapeutic treatment and also provide an opportunity for alternative remedies based on natural products (Fournier et al., 2010). Natural products, on the contrary, are complex and often contain many potentially active substances and even the ethical imperative for further scientific study on medicinal plants (Lans, 2007).

There are also large numbers of herbal medicines whose therapeutic potential have been assessed in a variety of animal models. Most assessments of herbal antidepressant activity were conducted using the rodent Forced Swimming Test (FST) and the Tail Suspension Test (TST) (Zhang, 2004). Both FST and TST are widely used to screen new antidepressant drugs (Porsolt et al., 1977; 1978). These studies have provided useful information for the development of new pharmacotherapies from medicinal plants for use in clinical psychiatry for the treatment of depression (Zhang, 2004). The other important reason for the popularity of the FST as a model is its ability to detect the antidepressant-like effects of drugs from a variety of classes after acute administration which allows for rapid screening of novel drugs (Cryan et al., 2005).

Interactions between monoamine neurotransmitters system including serotonin (5-hydroxytryptamine) (5HT), Noradrenaline (NA) and Dopamine (DA) in the brain along with their specific reuptake and receptor protein has gain so much interest in the spectrum of antidepressant studies (Yi et al., 2008). In plants, serotonin has been found in a wide range of plant species. Serotonin is predominantly distributed in reproductive as opposed to vegetative organs (Kang et al., 2009). For example, serotonin accumulates in the stinging nettle (Urtica dioica) (Kang et al., 2009) which belong to Urticaceae family.

In order to explore the rich biodiversity of the country and discover natural products, Pilea microphylla (Urticaceae) was investigated for antidepressant activity due to its rich flavonoid contents (Prabhakar et al., 2007; Modaressi Chahardehi et al., 2009). In the meanwhile, several reports had appeared showing that, Urtica dioica from the same family possess antidepressant like activity.

The previous study showed that this plant had antioxidant, antimicrobial activity (Modaressi Chahardehi et al., 2009) and also has anticancer activity (data not published). According to our previous data, we selected some best crude extract namely, methanol extract from extraction Method I (ME I), chloroform and ethyl acetate extracts from extraction method II (CE II and EAE II) for antidepressant activity on mice. This study was planned to evaluate the antidepressant action of Pilea microphylla and compare selected crude extracts of this plant with conventional antidepressant drugs using forced swimming and tail suspension models in mice. Also to explore if the immobility (it might be supposedly learned) can be forgotten as a consequence of the passage of time by means of increasing the time intervals (more than one time experiment). In this study, a variation of the original Porsolt et al. (1977) test was used which means placing the mice in the water tank in two occasions separated by different days and recording swimming activity automatically.

\section{MATERIALS AND METHODS}

\subsection{Animals}

Albino mice of either sex purchased from animal house, School of Medical Sciences, University of Tehran (Iran) and weighing 25-35 g were used. Animals were placed at Animal house, Department of Anatomy, School of Medical Sciences, University of Tehran, housed 6 per cage under a normal $12 \mathrm{~h} / 12 \mathrm{~h}$ light/dark schedule with the lights on at 07:00 am and had free access to water and food pellets. They were allowed at least 1 week to adapt to the laboratory prior to the administration. All efforts were made to minimize animal suffering and to reduce the number of animal used. All the drugs were administered intraperitoneally (i.p.) $30 \mathrm{~min}$ prior to FST.

\subsection{Forced Swimming Test (FST)}

Mice of either sex were individually forced to swim in an open cylindrical container (diameter $10 \mathrm{~cm}$, height $25 \mathrm{~cm}$ ), containing $19 \mathrm{~cm}$ of water at $25 \pm 1{ }^{\circ} \mathrm{C}$. The immobility time, defined as the absence of escapeoriented behaviors, such as swimming, was scored during 6min with the help of stop-watch, as described previously by (Eckeli et al., 2000). All the mice of either sex were divided in five different groups. The first group assigned as control receiving only vehicle $\left(\mathrm{NaCl} 5 \mathrm{~mL} \mathrm{~kg}^{-1}\right)$. The other groups received acute dose of extracts. The total duration of immobility was recorded during the last $6 \mathrm{~min}$ of the $10 \mathrm{~min}$ period, where the activity in the two first minutes is discarded (Porsolt, 1981). Each mouse was judged to be immobile when it ceased struggling and remained floating motionless in the water, making only those movements necessary to keep its head above water. A decrease in the duration of immobility is indicative of an antidepressant 
like effect. For the next exposure of crude extracts, FST of repetitive doses of crude extracts were assessed after 3 days of treatment within 30 min after the last dose of administration. During the test session, the immobility time was recorded. The mice were considered immobile when neither hind leg was moving; the mice were slightly hunched forward. Another reason for choosing this animal model is the correlation which is observed between results in this model and clinical potency, which is not found in any other models (Willner, 1984; Shah et al., 2006). A different interpretation of the FST holds that rats or mice, in this behavioral paradigm, learn to be immobile. Immobility is considered to be an adaptive response to the situation consisting of animals learning to keep their heads out of water with a minimum of energy expenditure (Parra et al., 1999).

\subsection{Tail Suspension Test (TST)}

The total duration of immobility induced by tail suspension test was measured according to the method described by Steru et al. (1985). Mice both acoustically and visually isolated were suspended $70 \mathrm{~cm}$ above the floor by adhesive tape placed approximately $1 \mathrm{~cm}$ from the tip of the tail. The total immobility period was scored manually during 6 min test session with the help of stopwatch. Immobility was defined as the absence of any limb or body movements, except for those caused by respiration or when they hung passively and completely motionless. The parameter obtained was the number of seconds spent immobile. Parameter used was the number of seconds spent immobile.

\subsection{Pharmacological Treatments}

In order to investigate the antidepressant-like effect of selected crude extracts of Pilea microphylla, it was administered (50 and $100 \mathrm{mg} \mathrm{kg}^{-1}$, i.p.) $30 \mathrm{~min}$ before the FST, TST tests. The Selective Serotonin Reuptake Inhibitors (SSRIs) antidepressant fluoxetine (diluted with normal saline) and haloperidol (diluted with sterile water) at concentration 10 and $1 \mathrm{mg} \mathrm{k} \mathrm{g}^{-1}$, respectively, were administered by i.p. route as positive controls $30 \mathrm{~min}$ before the FST and TST. The doses of the crude extracts used were selected on the basis of previous results (Mortality Dose Test) from our laboratory (data not shown).

\subsection{Statistical Analysis}

Data were expressed as the mean \pm Standard Error of Mean (SEM). Comparisons between experimental and control groups were performed by one-way Analysis of Variance (ANOVA) followed by Tukey`s HSD test when appropriate. $\mathrm{p}<0.05$ was considered significant.

\section{RESULTS}

During our first experiment, where the animals were repeatedly tested in water tank for forced swimming test, a statistically significant decrease in the activity was observed with intervals of up to three days. Such decrease resembles that reported by Porsolt (1981); Willner (1984) in rats and Parra et al. (1999) in albino mice.

According to FST results from the first day was shown in Table 1. A significant $(p<0.05)$ decrease in the duration of immobility was seen with two standard drug haloperidol and fluoxetine and all tested doses of selected extract except EAE II at dose of $50 \mathrm{mg} \mathrm{kg}^{-1}$ $(p<0.01)$ as compared to the control group.

In the first day, CE II in a dose of $50 \mathrm{mg} \mathrm{kg}^{-1}$ was more efficacious than fluoxetine in reducing the duration of immobility. However, in the third day, only CE II and EAE II at the high dose tested $\left(100 \mathrm{mg} \mathrm{kg}^{-1}\right)$ were more efficacious than fluoxetine. The results obtained after a single administration of the extract suspension showed that the immobility time of mice decreased dosedependently which mice were more active in both employed models and it means that the antidepressant effect was stronger. However, for all two doses administered there were differences compared to the control, that is, they led to reduction of immobility time.

In the FST at the third day at $100 \mathrm{mg} \mathrm{kg}^{-1}$ concentration it achieved by $46.18 \%$ for ME I, $67.70 \%$ for CEPM II and $75.97 \%$ for EAE II. However, a significant decrease of mobility in the third day of FST with respect to the first day was found in five of the six groups. The immobility of depressed mice (CE II and EAE II) at both concentrations is found to be increase when increased compared to the normal mice (control group). However, on treatment with selected crude extracts of $P$. microphylla, the immobility time significantly decreases at dose $50 \mathrm{mg} \mathrm{kg}^{-1}$ except ME II extract, when compared to the depressed mice. Positive control antidepressant drugs haloperidol and fluoxetine produced significant result on immobility time $(80.62 \%$ and $48.06 \%$ reduction respectively in FST test). Similar results of increased antidepressant effect, that is, of immobility time depending on the concentration administered which were achieved with the TST results (Table 1). 
Table 1. Antidepressant effect of Pilea microphylla extract

\begin{tabular}{|c|c|c|c|c|c|c|c|}
\hline \multirow[b]{2}{*}{$\begin{array}{l}\text { Name of } \\
\text { Extract }\end{array}$} & \multirow[b]{2}{*}{$\begin{array}{l}\text { Dose } \\
\left(\mathrm{mg} \mathrm{kg}^{-1}\right)\end{array}$} & \multicolumn{4}{|c|}{ Forced swimming test } & \multicolumn{2}{|c|}{ Tail suspension test } \\
\hline & & $\begin{array}{l}\text { Immobility time }{ }^{a} \\
\text { (s) at first day }\end{array}$ & $\begin{array}{l}\text { Change } \\
(\%)\end{array}$ & $\begin{array}{l}\text { Immobility time }{ }^{a} \\
\text { (s) at third day }\end{array}$ & $\begin{array}{l}\text { Change } \\
(\%)\end{array}$ & $\begin{array}{l}\text { Immobility } \\
\text { time }^{\text {a }}(\mathrm{s})\end{array}$ & $\begin{array}{l}\text { Change } \\
(\%)\end{array}$ \\
\hline Control & 0 & $379.0 \pm 31.5$ & - & $387.0 \pm 52.8$ & - & $326.3 \pm 30.4$ & 42.39 \\
\hline Haloperidol & 1 & $106.7 \pm 4.5^{* * *}$ & -71.84 & $75.0 \pm 8.2 * * *$ & -80.62 & $64.0 \pm 15.1 * * *$ & -80.39 \\
\hline Fluoxetine & 10 & $203.7 \pm 6.1 * * *$ & -46.25 & $201.0 \pm 7.0 * * *$ & -48.06 & $98.0 \pm 11.5^{* * *}$ & -69.97 \\
\hline \multirow[t]{2}{*}{ ME I } & 50 & $382.3 \pm 21.7 \mathrm{~ns}$ & 0.79 & $239.3 \pm 41.8^{*}$ & -38.17 & $188.0 \pm 9.5 * * *$ & -42.39 \\
\hline & 100 & $224.7 \pm 14.6^{* * *}$ & -40.71 & $208.3 \pm 6.5^{* *}$ & -46.18 & $146.3 \pm 10.2 * * *$ & -55.16 \\
\hline \multirow[t]{2}{*}{ CE II } & 50 & $189.3 \pm 10.3^{* * *}$ & -50.05 & $230.3 \pm 71.5^{*}$ & -39.62 & $353.0 \pm 21.9 \mathrm{~ns}$ & 8.00 \\
\hline & 100 & $180.7 \pm 16.5^{* * *}$ & -52.32 & $125.0 \pm 29.5^{* * *}$ & -67.70 & $249.7 \pm 20.8^{* * *}$ & -23.41 \\
\hline \multirow[t]{2}{*}{ EAE II } & 50 & $292.3 \pm 18.5^{* *}$ & -22.88 & $238.0 \pm 24.0^{*}$ & -38.50 & $253.0 \pm 9.2 * *$ & -22.39 \\
\hline & 100 & $219.7 \pm 15.5 * * *$ & -42.03 & $101.3 \pm 7.4^{* * *}$ & -75.97 & $73.0 \pm 5.3 * * *$ & -77.61 \\
\hline
\end{tabular}

and $\mathrm{ns}=\mathrm{Da}, \mathrm{n}=3$; Statistically significant difference compared to the
arferent significant compared to control (vehicle)

All crude extract showed significant $(\mathrm{p}<0.05)$ decrease in the duration of immobility in TST except CE II at dose of $50 \mathrm{mg} \mathrm{kg}^{-1}$ without any significant and EAE II at the same dose $(p<0.01)$. However, EAE II exhibited highest decrease of duration immobility time in TST (77.61\%) followed by haloperidol as a positive control (80.39\%).

In the present study, our results demonstrate that the acute treatment with selected crude extracts of Pilea microphylla produced a significant antidepressant-like response in both FST and TST. The antidepressant-like effect of the extract was found to be significant at dose of $50 \mathrm{mg} \mathrm{kg}^{-1}$, followed by an increase in the immobility time at doses above $100 \mathrm{mg} \mathrm{kg}^{-1}$. For further process, we selected CE II extract for fractionation (according to its high extraction yield (\%), antimicrobial, anticancer activities). EAE II also exhibited best results, due to achieve low yield of extraction, we did not follow further with this extract.

According to polarity of CE II to obtain terpernoids and flavonoids and flavonols as the major constituent was found. In TLC chromatogram of CE II to get fractionation using EtOAc: n-Hexane (4:16) under UV light, flavonols at $98.68 \mathrm{R}_{\mathrm{f}}$ value was appeared at end of TLC in bright yellow spots in UV light and without colour in visible light. Some flavonoids like biflavones were appeared in high $\mathrm{R}_{\mathrm{f}}$ value. According to Harborne (1980), flavones are widespread in leaves.

Most bands in UV light were appeared in red and dark red colour. They are phenolic compounds and dark red or bright orange in UV light one of the colour properties of flavonoid in ultraviolet light, although in visible colour these spot in bright yellow.

Majority of bands under visible light represented in green colour except the last band (eighth band) appeared in yellow colour. This band could be in flavonols group. Flavonols are appeared in bright yellow and bright yellow fluorescent in high Rf value. Although some highly methylated flavonols behave similarly (Harborne, 1980).

\section{DISCUSSION}

In FST, mice are forced to swim in a restricted space from which they cannot escape and are induced to a characteristic behavior of immobility. This behavior, reflecting a state of despair, is reduced by several agents that are therapeutically effective in human depression. The immobility displayed in rodents subjected to an unavoidable and inescapable stress has been hypothesized to reflect behavioral despair, which in turn may reflect depressive disorders in humans. In fact, there is a significant correlation between the potency of antidepressants in both forcedswimming and tailsuspension tests and clinical potency of the drugs. The decrease in the immobility time is accompanied with the increase in swimming time.

Comparing the results obtained by the two models employed in this study, which use different stress situations to induce states of terror and despair, it can be observed that the effect of the extract on the reduction of immobility time was obtained more strongly in the forced-swimming model than in the TST (Porsolt, 1987). According to our results the mean value of immobility time for the control group of animals was higher in the forced swimming than in the tail suspension test.

EAE II as a non-polar extract treatment (at $100 \mathrm{mg} \mathrm{kg}^{-1}$ ) reduced the time of immobility in the FST, similar to the antidepressant fluoxetine (positive control), which is a selective serotonin reuptake inhibitor (Cryan et al., 2005; 
Bernardi et al., 2010). Our non-polar extracts (CE II and EAE II) confirmed our results by Bernardi et al. (2010).

However, several classes of compounds have been found in members of this family. These are the proanthocyanidins and flavonols. When the proanthocyanidins are present, cyanidin is the compound identified. When the flavonols are present, quercetin is commonly found. Sometimes, both kaempferol and quercetin can be found. Ellagic acid has been reported to be absent in eight species and five genera (Avalos and Maibach, 2000). According to results of phytochemical screening and the literature, the antidepressants like potential might be due to the presence of alkaloids, glycosides and flavonoids. Flavanoids glycosides are mostly hydrolysed into their aglycons by mucosal and bacterial enzymes in the intestines and then converted to conjugated metabolites during the absorption process.

Transportation of these metabolites into the brain tissues via the blood brain barrier and their effect on the Central Nervous System (CNS) has been recently argued (Umedavi et al., 2011). It seems one of the antidepressant mechanisms of $P$. microphylla is thought to involve flavonoid glycosides, that reach the brain tissues through to involve flavonoid glycosides, which reach the brain tissues through the metabolizing process, protecting brain function from CNS disturbance and consequently, exerting an antidepressant effect. In the present study, EAE II at highest dose tested $\left(100 \mathrm{mg} \mathrm{kg}^{-1}\right)$ was superior to fluoxetine in both the experimental models (FST and TST). Exact mechanisms underlying the antidepressant action cannot be concluded at the moment due to the presence of large number of phytochemicals in the P. microphylla. However, the antidepressant activity may be due to the presence of flavonoids in the extracts.

Rocha et al. (2007) reported that Cecropia glazioui from Urticaceae family as same as $P$. microphylla, had antidepressant-like effect. The effect was enhanced after purification of the active extract. Catehins, procyanidins and flavonoids were the main constituents of the purified active fraction. So far, in vitro studies exhibited that catechin $(4 \alpha \rightarrow 8)$ ent-catechin (Procyanidin B3 isomer), catechin and epicatechin $(4 \alpha \rightarrow 8)$ epicatechin (Procyanidin B2) inhibited 5-HT, NA and DA uptakes in brain synaptosomes but the flavonoids isoorientin and isovitexin did not. Rocha et al. (2007). Found that catechin and procyanidins are the major active substances in vitro and may contribute to the antidepressant-like effect produced by C. glazioui.

The initial antidepressant action followed by the appearance of depression-like symptoms may be attributed to the active flavonoid contents of the plant.
The presence of such structurally similar flavonoids with opposing effects on motor activity may be the cause of antidepressant-like action with low doses followed by an increase in immobility time at higher doses of the extract (An et al., 2008). P. microphylla possesses profound antidepressant-like property at low doses and may be explored for developing antidepressant drugs derived from natural products.

Although the mean value of immobility time for the control group of animals was higher in the forced swimming test than in the tail suspension test, this difference was not significant. However, when comparing the changes of immobility time in extract-treated animals, expressed as the percent of control values, between two tests, the reduction of immobility time was more marked in the FST method. This means that FST is more sensitive and better reflects the state of depression (Bach-Rojecky et al., 2004). Nonetheless, pharmacokinetic studies are still needed to establish a correlation between the in vitro molecular interactions of these compounds and in the in vivo activity of this plant extracts.

\section{CONCLUSION}

In conclusion, the present study indicates that Pilea microphylla produces a specific antidepressant-like effect in animal models predictive of antidepressant properties, forced swimming test and tail suspension test. Moreover, the effect of the acute or repeated administration of this extract was similar to the action produced by the classical antidepressant fluoxetine and haloperidol. Future experiments are needed to further characterize the mechanism of the antidepressant effect of P. microphylla, especially of single compounds of the extract, as the only natural drug with antidepressant activity.

\section{ACKNOWLEDGMENT}

This material is based upon work supported by a grant from Universiti Sains Malaysia (USM). We also thank USM because this research was partially supported by the provided fellowship.

\section{REFERENCES}

An, L., Y.Z. Zhang, N.J. Yu, X.M. Liu and N. Zhao et al., 2008. Role for serotonin in the antidepressantlike effect of a flavonoid extract of Xiaobuxin-Tang. Pharmacol. Biochem. Behav., 89: 572-580. DOI: 10.1016/j.pbb.2008.02.014 
Avalos, J. and H.I. Maibach, 2000. Beneficial uses of Plants. In: Dermatolo Botany, Avalos, J. and H.I. Maibach (Eds.), CRC Press LLC, Boca Raton, ISBN-10: 0849373611, pp: 1-2.

Bach-Rojecky, L., Z. Kalodera and I. Samarzija, 2004. The antidepressant activity of Hypericum perforatum L. measured by two experimental methods on mice. Acta Pharm., 54: 157-162. PMID: 15274759

Bernardi, M.M., T.B. Kirsten, S.A. Salzgeber, E.L. Ricci and P. Romoff et al., 2010. Antidepressant-like effects of an apolar extract and chow enriched with Nepeta cataria (catnip) in mice. Psychol. Neurosci. DOI: $10.3922 /$ j.psns.2010.2.015

Cryan, J.F., C. Mombereau and A. Vassout, 2005. The tail suspension test as a model for assessing antidepressant activity: Review of pharmacological and genetic studies in mice. Neurosci. Biobeh. Rev., 29: 571-625. DOI: 10.1016/j.neubiorev.2005.03.009

Eckeli, A.L., F. Dach and A.L.S. Rodrigues, 2000. Acute treatments with GMP produce antidepressant-like effects in mice. Neuro Rep., 11: 1839-1843. DOI: 10.1097/00001756-200006260-00008

Fournier, J.C., R.J. DeRubeis, S.D. Hollon, S. Dimidjian and J.D. Amsterdam et al., 2010. Antidepressant drug effects and depression severity a patient-level meta-analysis. J. Am. Med. Assoc., 303: 7-53. DOI: 10.1001/jama.2009.1943

Harborne, J.B., 1980. Phytochemical Methods: A Guide to Modern Techniques of Plant Analysis. 1st Edn., Chapman and Hall, London, ISBN-10: 041223050X, pp: 278.

Kang, K., Y.S. Kim, S. Park and K. Back, 2009. Senescence-induced serotonin biosynthesis and its role in delaying senescence in rice leaves. Plant Physiol., 150: 1380-1393. DOI: 10.1104/pp.109.138552

Lans, C., 2007. Ethnomedicines used in Trinidad and Tobago for reproductive problems. J. Ethnobiol. Ethnomed., 3: 13-13. DOI: 10.1186/1746-4269-3-13

Modaressi Chahardehi, A.M., D. Ibrahim and S.F. Sulaiman, 2009. Antioxidant, antimicrobial activity and toxicity test of Pilea microphylla. Int. J. Microbiol., 2010: 826830-826835. DOI: 10.1155/2010/826830

Parra, A., C. Vinader-Caerols, S. Monleon and V.M. Simon, 1999. Learned immobility is also involved in the forced swimming test in mice. Psicothema, 11: 239-246.
Porsolt, R.D., 1981. Behavioral Despair. In: Antidepressants: Neurochemical, Behavioral and Clinical Perspectives, Enna, S.J. (Ed.). Raven Press, New York, ISBN-10: 0890045348, pp: 121: 139.

Porsolt, R.D., 1987. Animal models of depression: Utility for transgenic research. Rev. Neurosci., 11: 53-58. DOI: 10.1515/REVNEURO.2000.11.1.53

Porsolt, R.D., A. Bertin and M. Jalfre, 1977. Behavioral despair in mice: A primary screening test for antidepressants. Arch. Int. Pharmacodyn Ther., 229: 327-336. PMID: 596982

Porsolt, R.D., L.G. Anton, N. Blavet and M. Jalfre, 1978. Behavioural despair in rats: A new model sensitive to antidepressant treatments. Eur. J. Pharmacol., 47: 379-391. PMID: 204499

Posser, T., M.P. Kaster, S.C. Barauna, J.B.T. Rocha and A.L.S. Rodrigues et al., 2009. Antidepressant-like effect of the organoselenium compound ebselen in mice: Evidence for the involvement of the monoaminergic system. Eur. J. Pharmacol., 602: 8591. DOI: 10.1016/j.ejphar.2008.10.055

Prabhakar, K.R., V.P. Veerapur, P. Bansal, V.K. Parihar and M.R. Kandadi et al., 2007. Antioxidant and radioprotective effect of the active fraction of Pilea microphylla (L.) ethanolic extract. Chemico-Biol., Interact., 165: 22-33. DOI: 10.1016/j.cbi.2006.10.007

Rocha, F.F., M.T.R. Lima-Landman, C. Souccar, M.M. Tanae and T.C.M.D. Lima et al., 2007. Antidepressant-like effect of Cecropia glazioui Sneth and its constituents-In vivo and in vitro characterization of the underlying mechanism. Phytomedicine, 14: 396-402. DOI: 10.1016/j.phymed.2007.03.011

Shah, P.C., N.A. Trivedi, J.D. Bhatt and K.G. Hemavathi, 2006. Effect of Withania somnifera on forced swimming test induced immobility in mice and its interaction with various drugs. Indian J. Physiol. Pharmacol., 50: 409- 415. PMID: 17402272

Steru, L., R. Chemat, B. Thierry and P. Simon, 1985. The tail suspension test: A new method for screening antidepressants in mice. Psychopharmcalogy, 85: 367-370. PMID: 3923523

Umedavi, P., S. Murugan, S.J. Suganthi and S. Subakanmani, 2011. Evaluation of antidepressant like activity of Cucurbita pepo seed extracts in rats. Int. J. Curr. Pharmaceutical Res., 3: 108-113. 
Amir Modarresi Chahardehi et al. / American Journal of Agricultural and Biological Sciences 8 (1) (2013) 75-81

Willner, P., 1984. The validity of animal models of depression. Psychopharmacolgy, 83: 1-16. PMID: 6429692

Yi, L.T., J.M. Li, Y.C. Li, Y. Pan and Q. Xu et al., 2008. Antidepressant-like behavioral and neurochemical effects of the citrus-associated chemical apigenin. Life Sci., 82: 741-751. DOI: 10.1016/j.lfs.2008.01.007
Zhang, Z., 2004. Therapeutic effects of herbal extracts and constituents in animal models of psychiatric disorders. Life Sci., 75: 1659-1699. DOI: 10.1016/j.lfs.2004.04.014 